\title{
Indian nurses' views on a collaborative model of best practices: Evidence-based practice, job satisfaction, learning environment, and nursing quality
}

\author{
Kaisa Bjuresäter*1, Sister Tessy Sebastian ${ }^{2}$, Bhalchandra Kulkarni ${ }^{2}$, Elsy Athlin ${ }^{1}$ \\ ${ }^{1}$ Institution of Health Sciences, Karlstad University, Karlstad, Sweden \\ ${ }^{2}$ College of Nursing, Datta Meghe Institute of Medical Science, Sawangi, India
}

Received: March 28, 2018

DOI: $10.5430 /$ jnep.v8n9p87

\author{
Accepted: April 18, 2018 \\ Online Published: April 26, 2018 \\ URL: https://doi.org/10.5430/jnep.v8n9p87
}

\begin{abstract}
Introduction: This study is a part of a project aimed at implementing and evaluating the Collaborative Model of Best Practice, (CMBP) to promoting evidence-based practice (EBP) in health care contexts. The aim of the study was to assess nurses' interest, attitudes, utilization, and views on promotors of and resources related to EBP before and after taking part in the CMBP project, and to investigate their views on the CMBP in relation to collaboration between the academy and clinical practice, the learning environment, job satisfaction, and nursing quality.

Methods: A descriptive, comparative design was used with pre- and post-test measurements. The Research Utilization Questionnaire (RUQ) and study-specific questions were distributed to ward nurses $(n=67)$ in a rural Indian hospital.

Results: Most of the nurses thought that the CMBP had a positive impact on quality of care, on their attitudes to, interest in, and knowledge EBP, and on their job satisfaction. They also considered that the collaboration between the nursing college and clinical practice had a positive impact on the learning environment and that more resources were available at the end of the project.

Conclusions: The CMBP project was an attempt to improve the quality of care for patients and the learning environment for nursing students and nurses on the project wards. The results indicated fulfilment of these goals, which strengthens the usability of the model. Implementation of EBP is challenging and requires long-lasting activities and comprehensive support from leaders and facilitators. More studies are needed in which EBP is systematically implemented, accomplished, evaluated, and reported.
\end{abstract}

Key Words: Collaboration, Evidence-based practice, Facilitator, Nursing quality, Research utilization

\section{INTRODUCTION}

\subsection{Background}

For decades health care authorities around the world have recommended that health professionals base their decisions on evidence. As nurses are the largest group of health providers and have a major role in designing and delivering effective and efficient care to patients in different health care contexts, their perceptiveness and competence to use research findings in their daily work has been highlighted as imperative. ${ }^{[1-3]}$ As much as two decades ago Royle \& Blythe ${ }^{[4]}$ stressed that much of the responsibility for evidence-based practice (EBP) is placed on individual nurses, as all nurses have a professional responsibility to provide patient care based on the best available evidence. However, many studies have shown the complexity of implementing a culture of EBP in daily work. ${ }^{[5-8]}$ Factors often reported to hinder EBP are nurses'

*Correspondence: Kaisa Bjuresäter; Email: kaisa.bjuresater@kau.se; Address: Institution of Health Sciences, Karlstad University, Karlstad, Sweden. 
beliefs and attitudes about EBP and their involvement in research activities and information seeking, educational and socio-economic factors, time, leadership, learning culture, support, and access to libraries and the internet. ${ }^{[9-12]}$

In response to proposals for EBP in nursing care, nursing education has been transferred to universities and academic colleges in most developed countries, where nurses are expected to be trained in thinking and using EBP in their basic training. To be considered ready to take an active role in EBP after graduation, nursing students are expected to be able to search for research findings, understand them, and compare them with their clinical experiences in practice. This has led to a new set of challenges for all parties - lecturers, nursing students, and clinical nurses - involved in nursing programmes. ${ }^{[13]}$ Because nursing students to a great extent model their professional role in practice ${ }^{[14]}$ it is important for them to meet registered nurses who believe in the importance of critical thinking and using research findings in their daily work.

During the last two decades an overwhelming array of strategies and models for implementing EBP have been published, some of which we found especially valuable for our proposed project. Kitson et al. ${ }^{[15]}$ suggested a framework underlining the necessity of both 'bottom-up' and 'top-down' strategies in the development of care. The framework of McCormack et al., ${ }^{[16]}$ based on critical social philosophy, emphasised 'collaboration, mutual support, critical challenge, reflexivity and empowerment of individuals to change' (p. 259). These authors also stressed the necessity of a systematic approach integrating learning, development, and research activities. Rycroft-Malone et al. ${ }^{[17]}$ developed the Promoting Action on Research Implementation in Health Services (PARISH), a complex framework highlighting the need for successful EBP work to take into consideration all levels of the health care system. Rosswurm and Larrabee ${ }^{[18]}$ proposed a practical model based on theory and research, including change theory, which offers a broad basis for implementing changes in practice. Many collaborative models argue for the use of nurse lecturers to facilitate the development of EBP in patient care, with nurse lecturers, nursing students, and clinical nurses working together. ${ }^{[19-21]}$

\subsection{Collaborative model for best practice (CMBP)}

The CMBP ${ }^{[20,22]}$ used in our project was influenced by the models described in Section 1.1. The overall aim of the model is to promote EBP in different health care contexts through close collaboration between the nursing academy and different levels of authority in the clinical fields where nursing students are trained during their education. Embedded in the model is the EBP process, in which involve- ment, critical reflection, and facilitation of nursing personnel are considered fundamental to achieving change. Through increased awareness and learning, nurses are expected to change their actions towards higher quality daily care based on research findings. The EBP process includes (1) identification of an area in patient care for a critical review and improvement of current practice, (2) a search for evidence in the research literature, (3) critical appraisal of the evidence, (4) application of the evidence to practice, and (5) evaluation of the effectiveness in practice of the chosen evidence. ${ }^{[23]}$

\subsection{The project}

With this background a collaborative project was carried out at Swedish and Indian institutions in 2011-2013 with the overall aim of implementing and evaluating the CMBP for promoting EBP in different health care contexts. The project was conducted in four Swedish and four Indian medical/surgical wards, led by a project management group of researchers and head nurses. A facilitator group of two experienced nurses and one clinical nurse lecturer was also chosen for each ward. Before the first step of the EBP process, these facilitators participated in a two-week course on the facilitator role and EBP and were trained in literature searches in databases, in reading, analysing, and understanding research findings, and in presenting summaries of findings to others. Throughout the project, they were supported by the project management in anchoring, supporting, and controlling the EBP process on their wards.

On each ward the nursing personnel, the head nurse, and facilitators together selected an area of nursing for quality improvement. The EBP process was then followed step by step. During the implementation phase (step 4) the facilitators checked that protocols and checklists for new routines were followed each week and provided feedback to the ward nurses. Because the CMBP model concerns improvement of nursing quality in practice, all nurses and nursing students on the ward were involved. All activities in the project were carried out as similarly as possible in both countries and were evaluated with a focus on nursing quality, learning environment, nurses' and nursing students' attitudes to and knowledge of EBP, job satisfaction, cooperation between the academy and clinical practice, and the facilitator role. The current paper reports the Indian part of the project aimed at assessing nurses' interest in, attitudes to, and use of research and their views on the promotors of and resources related to EBP before and after taking part in a CMBP project. Another aim was to investigate nurses' views on the CMBP in relation to the collaboration between the academy and clinical practice, the learning environment, their job satisfaction, and nursing quality. 


\section{Methods}

\subsection{Design}

A descriptive, comparative design was used with pre- and post-test measurements taken to evaluate the CMBP's effectiveness .

\subsection{Research questions}

The research focused on following areas: attitudes, interest in and knowledge of research utilisation, available resources for the use of research, quality of care, work satisfaction, learning environment, and collaboration between nursing education and clinical practice.

\subsection{Participants and data collection}

The participants were registered nurses from the four project wards in a rural hospital in the middle of India. Data were collected at baseline before the improvement area was identified (November 2011) and at the end of the implementation phase (July 2013). All nurses who worked on the chosen wards during the project received information about the study orally from the project management and via an informational letter. All of them (72) agreed to participate in the project and 67 answered the questionnaires at baseline (93\%). At the end point, 67 nurses worked on the wards and 63 of those (94\%) answered the questionnaires. The characteristics of the pre-and post-test groups are presented in Table 1.

Table 1. Characteristics of the pre-and post-test groups

\begin{tabular}{|c|c|c|}
\hline & Baseline & Endpoint \\
\hline & $\begin{array}{l}\text { Mean } \\
\text { (Range) }\end{array}$ & $\begin{array}{l}\text { Mean } \\
\text { (Range) }\end{array}$ \\
\hline Age (years) & $28.5(21-54)$ & $31.3(22-56)$ \\
\hline Work experience as a nurse (years) & $4.7(0-17)$ & $7.6(2-18)$ \\
\hline Academic degree & N (\%) & N (\%) \\
\hline Associate degree & $4(5.8)$ & 0 \\
\hline Diploma degree & $61(88.4)$ & $57(90.5)$ \\
\hline Unknown & $4(5.8)$ & $6(9.5)$ \\
\hline
\end{tabular}

We used the Research Utilization Questionnaire (RUQ) initially developed by Champion and Leach ${ }^{[24]}$ and further revised by Pettengill et al. ${ }^{[2]}$ and Humphris et al. ${ }^{[26]}$ The first part of the RUQ questionnaire comprises 29 items covering three domains: attitudes towards research (12 items), availability and support (8 items), and research use in daily practice $(9$ items). A 5-point Likert scale was used where $1=$ strongly disagree and $5=$ strongly agree. Higher values indicate a more positive attitude towards research utilisation. The second part of the RUQ asks about research-related resources (11 items), seeking research (1 item), factors that may hinder the use of research findings (10 items, not used in this study) and factors that may help the use of research findings (10 Published by Sciedu Press items) (Boström et al., 2006). The RUQ questionnaire has shown good psychometric properties in previous studies. Internal consistency have ranged from 0.84 to 0.94 and content validity has confirmed by an expert panel. ${ }^{[24,27,28]}$ A factor analysis have performed and resulted in four domains. ${ }^{[24]}$ Study-specific questions (18 items) about the CMBP model, nursing quality, work satisfaction, learning environment, and cooperation were also included. For these questions respondents were asked to rate their opinion on a 10-point scale (1 = very low/very little and $10=$ very high/very much). Questions about demographic data (age, education, years of work experience) were also added.

\subsection{Data analysis}

IBM SPSS statistics version 22 was used to analyse the data. Mann Whitney U test was used to compare differences in attitudes between two independent groups, and Pearson Chi-square was used to compare differences in proportions between the two groups regarding available resources. The tests were two-tailed, and $p<.05$ was considered statistically significant. ${ }^{[29]}$

\subsection{Ethical considerations}

The ethics committee at the local university approved the research proposal (Ref no. DMIMS/IEC/12-13/1009). The participants were informed about the study aims, confidentiality of the data, and their freedom to withdraw, and their written consent was obtained.

\section{RESUlts}

\subsection{Attitudes towards research}

The results show that the nurses' attitudes to using research utilization and EBP were positive at baseline, but they scored even higher values for most items at the end point, which shows that their positive attitudes had significantly improved (see Table 2). For example, higher values were scored for Understanding research helps me practice professional nursing (4.12/4.48; $p=.001)$, I think research is exciting (3.93/4.39; $p=.001)$, and Research is stimulating $(3.94 / 4.45 ; p=.001)$.

\subsection{Availability and support}

There were statistically significant differences between preand post-test scores on the nurses' views of the availability of research and support in using it (see Table 2). Examples are I have access to research findings where I work (3.78/4.20; $p=$ .001), My superior supports utilization of research (3.95/4.38; $p=.001)$, The clinical team I work with supports research findings (3.96/4.52; $p=.001)$, and In service education about research findings is given in my hospital $(3.68 / 4.52 ; p=$ $.001)$. 


\subsection{Research use}

The results show statistically significant pre-/post-test improvements in most items on nurses' use of research (see Table 2). Higher values were scored, for example, for Nursing research is conducted in my hospital $(3.87 / 4.42 ; p=$
$.001)$, I base my practice on research $(3.93 / 4.41 ; p=.001)$, I actively search for research related to my clinical practice $(3.80 / 4.46 ; p=.001)$, and I help others to use research in practice $(3.80 / 4.46 ; p=.001)$.

Table 2. Attitudes to and interest in research utilization and availability and support

\begin{tabular}{|c|c|c|c|}
\hline & $\begin{array}{l}\text { Baseline (N = 67) } \\
\text { Mean (SD) }\end{array}$ & $\begin{array}{l}\text { Endpoint (N = 63) } \\
\text { Mean (SD) }\end{array}$ & $p$ \\
\hline \multicolumn{4}{|l|}{ Attitudes } \\
\hline I would change my practice based on research findings & $3.98(0.61)$ & $4.40(0.49)$ & .001 \\
\hline I want to base my practice on research & $4.0(0.52)$ & $4.31(0.50)$ & .001 \\
\hline Nursing practice should be based on research & $4.24(0.68)$ & $4.42(0.61)$ & 124 \\
\hline Studying research is a waste of time & $2.07(1.14)$ & $1.64(0.70)$ & .045 \\
\hline Understanding research helps me practice professional nursing & $4.12(0.62)$ & $4.48(0.50)$ & .001 \\
\hline I think research is exciting & $3.93(0.82)$ & $4.39(0.66)$ & .001 \\
\hline Research is stimulating & $3.94(0.83)$ & $4.45(0.59)$ & .001 \\
\hline Research is understandable & $4.13(0.45)$ & $4.31(0.71)$ & .016 \\
\hline Research is a dull, boring subject & $2.12(1.08)$ & $2.06(1.28)$ & .463 \\
\hline Research is not relevant to use in practice & $2.62(1.13)$ & $2.03(1.16)$ & .001 \\
\hline Practice based on research findings saves time & $3.74(0.98)$ & $4.12(0.79)$ & .019 \\
\hline Research findings are too complicated to use in practice & $2.74(1.14)$ & $2.55(1.52)$ & .206 \\
\hline \multicolumn{4}{|l|}{ Availability and support } \\
\hline The clinical team I work with supports research findings & $3.96(0.65)$ & $4.52(0.59)$ & .001 \\
\hline My superior supports the use of research & $3.95(0.81)$ & $4.38(0.66)$ & .001 \\
\hline The quality of research is not adequate for application to practice & $2.70(0.96)$ & $2.54(1.33)$ & .151 \\
\hline I have access to research findings where I work & $3.78(0.69)$ & $4.20(0.67)$ & .001 \\
\hline I have time to read research when I am on duty & $3.01(1.04)$ & $3.47(1.22)$ & .017 \\
\hline Nursing research is conducted in my clinical area & $3.64(0.93)$ & $4.44(0.50)$ & .001 \\
\hline Nursing research is conducted in my hospital & $3.87(0.83)$ & $4.42(0.53)$ & .001 \\
\hline In service education about research findings is given in my hospital & $3.68(1.01)$ & $4.52(0.50)$ & .001 \\
\hline \multicolumn{4}{|l|}{ Research use } \\
\hline I base my practice on research & $3.93(0.72)$ & $4.41(0.58)$ & .001 \\
\hline My nursing care decisions are based on research & $3.86(0.86)$ & $4.17(0.73)$ & .034 \\
\hline I do not use research in my day-to-day practice & $2.59(1.24)$ & $2.37(1.32)$ & .253 \\
\hline I apply research results to my own practice & $3.86(0.90)$ & $4.30(0.68)$ & .002 \\
\hline I use research findings in planning patient care & $3.87(0.86)$ & $4.30(0.49)$ & .002 \\
\hline I help others to use research in practice & $3.91(0.75)$ & $4.38(0.52)$ & .001 \\
\hline I use research to guide my nursing practice & $3.89(0.82)$ & $4.50(0.59)$ & .001 \\
\hline I am unable to use research in my work & $2.65(1.24)$ & $1.73(0.93)$ & .001 \\
\hline I actively search for research related to my clinical practice & $3.80(0.95)$ & $4.46(0.69)$ & .001 \\
\hline
\end{tabular}

* Mann Whitney U test

\subsection{Resources}

Statistically significant pre-/post-test differences were also found on items related to the research resources available to the nurses. For example, at baseline, 36\% $(n=25)$ of the nurses answered that they had research assistants at the hospital, $42 \%(n=29)$ that they had access to computer service and the Internet, $42 \%(n=29)$ that they had support from a librarian, and $35 \%(n=24)$ that they had time to conduct research during work hours. At the end point, almost all nurses answered that they had the resources necessary to use research findings (see Table 3).

\subsection{Impact of the CMBP project}

The results show that the nurses' views on EBP, nursing quality, job satisfaction, learning environment, and collaboration between the academy and clinical practice scored high on 
all items from the beginning of the project, and at end point they scored significantly higher (see Table 4). Responses to the final questions about the project show that the nurses had been very involved in the project (mean $=8.68$ ). Taking part in the CMBP project had improved their understanding of the importance of EBP (8.75) and their learning environment (8.76) and that of students (8.73), had contributed to new routines in their daily work (9.00), and had improved the quality of care (8.92). Finally, the nurses scored the CMBP very high on improving collaboration between the academy and clinical practice (8.90). The support from the facilitator group was scored very important for implementing EBP by most of the nurses: support from nurse lecturers $=8.30$, from experienced nurses $=8.20$, and from head nurses $=7.90$.

Table 3. Available resources (promotors) for use of research. The table shows number of persons who currently have resources to assist for using research findings

\begin{tabular}{|c|c|c|c|}
\hline & $\begin{array}{l}\text { Baseline } \\
\text { N (\%) }\end{array}$ & $\begin{array}{l}\text { Endpoint } \\
\text { N (\%) }\end{array}$ & $p$ \\
\hline Opportunity to consult a skilled researcher & $33(48)$ & $63(100)$ & .041 \\
\hline Research assistant staff in the hospital & $25(36)$ & $63(100)$ & .142 \\
\hline Computer services to access the Internet & $29(42)$ & $63(100)$ & .001 \\
\hline A library of current journals and books containing research and research methods & $35(51)$ & $63(100)$ & .004 \\
\hline Support from a librarian & $29(42)$ & $63(100)$ & .001 \\
\hline Statistical support & $40(58)$ & $63(100)$ & .009 \\
\hline Deputation with pay to attend research conferences & $29(42)$ & $59(94)$ & .416 \\
\hline Clerical services to assist research activities & $25(36)$ & $63(100)$ & .106 \\
\hline A hospital research committee & $32(46)$ & $63(100)$ & .162 \\
\hline Time to conduct research during work hours & $24(35)$ & $63(100)$ & .459 \\
\hline Support from nurse lecturer from Nursing College & $48(70)$ & $63(100)$ & .237 \\
\hline
\end{tabular}

* Pearson Chi-Square test

\section{Discussion}

In the last few decades many studies have been published on nurses' attitudes to, knowledge of, interest in, and use of research findings in practice. Similarly, nurses' perceptions of barriers and promotors to EBP have been frequently reported. Over time, many models have also been created as well about how to succeed in implementing EBP through collaboration between nursing colleges and nursing practice, in which the role of the nursing lecturer as a facilitator has been highlighted. However, only a few scientific papers have reported on the practical use and evaluation of such models. Therefore, the present study should be of interest as it is a part of a collaborative project with the overall aim of implementing and evaluating the CMBP.

The findings of this study show that the CMBP was broadly successful. Most nurses in the study scored the model as having impacted positively on the quality of care on the ward, on their attitudes to, interest in, and knowledge about EBP, and on their job satisfaction. The nurses also considered that the collaboration between nursing colleges and clinical practice facilitated by the model had had a positive impact on the learning environment on the wards. Notably is that from the beginning of the project the nurses had rather positive attitudes to EBP and scored high values on their attitudes to the use of research and EBP. They also scored initially high values on their knowledge and use of EBP in their daily work. Despite these positive early scores, their attitude to using EBP, knowledge about EBP, and interest for research significantly improved after 20 months' use of the CMBP. During this period the ward nurses had continuous support and training in the EBP process from the facilitators (ward nurses and nurse lecturers). Our results can be compared with those of several recent studies highlighting nurses' overall positive attitudes to EBP despite their various levels of knowledge and skills. ${ }^{[30-32]}$ This may indicate that nurses in studies of this type are initially inclined to overestimate their own knowledge and use of EBP, knowing what is expected of them, but also to lack real knowledge about EBP. Nurses' knowledge and skills related to literature searches, analysis, and how to implement evidence-based interventions in nursing care seem to be unsatisfactory.

More than a decade ago, Gerrish ${ }^{[33]}$ found that nurses were rather well-skilled in assessing and reviewing research reports, but they were less confident about how to change practice. Currently it seems obvious that nurses are aware of the importance of EBP and the use of research, ${ }^{[34,35]}$ but our results show that their knowledge and skills in implementing evidence-based interventions can be improved. Several 
studies have found a connection between the use of EBP and nurses' knowledge and skills ${ }^{[34,36]}$ and have shown that nurses' knowledge and skills improve after educational interventions. ${ }^{[37-39]}$ However, it has been difficult to prove the appropriate form and content of such education. ${ }^{[36]}$ Mentorship and continuing education are often pointed to as successful strategies. ${ }^{[34,40]}$ In our study, the facilitators trained together in literature searching, analysing scientific articles, the EBP implementation process, and the facilitator role. Throughout the project, they were expected to stimulate and increase the nurses' interest, awareness, and engagement in EBP, and to discuss EBP in daily caring situations. They also gave weekly feedback to all the nurses in ward meetings involving the head nurses. ${ }^{[22]}$ Based on our results, we would stress that a facilitator group including a nurse from the ward and a nurse lecturer from the academy, who provide practical support to the nurses on the ward, may be a factor in the successful implementation and development of EBP.

Table 4. Nurses' views on the CMBP model in relation to collaboration between the academy and clinical practice, evidence-based practice, learning environment, work satisfaction, and nursing quality (baseline and endpoint)

\begin{tabular}{|c|c|c|c|}
\hline & $\begin{array}{l}\text { Baseline } \\
(\mathrm{N}=65) \\
\text { Mean (SD) }\end{array}$ & $\begin{array}{l}\text { Endpoint } \\
(\mathrm{N}=63) \\
\text { Mean (SD) }\end{array}$ & $p$ \\
\hline Collaboration between nursing education and nurses in clinical practice & $6.75(1.68)$ & $8.79(0.88)$ & .001 \\
\hline Knowledge in EBP & $7.05(1.64)$ & $8.78(0.77)$ & .001 \\
\hline Interest in EBP & $7.31(1.70)$ & $8.78(0.77)$ & .001 \\
\hline Importance of EBP for quality of care & $7.69(1.73)$ & $8.90(0.79)$ & .001 \\
\hline Attitudes to the learning environment in the ward for nursing students? & $6.72(2.06)$ & $8.71(0.83)$ & .001 \\
\hline Own attitudes to the learning environment in the ward & $7.22(1.87)$ & $8.81(0.91)$ & .001 \\
\hline Satisfaction with own work & $7.18(2.23)$ & $8.65(1.05)$ & .001 \\
\hline Own contribution to quality of care & $7.00(1.50)$ & $8.89(0.78)$ & .001 \\
\hline Opinion of overall quality of care at the ward & $7.15(1.88)$ & $8.75(0.93)$ & .001 \\
\hline Own involvement in the project* & -- & $8.68(0.85)$ & \\
\hline The nurse facilitators have been important for implementation of EBP* & -- & $8.20(0.70)$ & \\
\hline The nurse lecturer facilitators have been important for implementation of EBP* & -- & $8.30(0.70)$ & \\
\hline The nurse leaders at the ward have been important for implementation of EBP* & -- & $7.90(0.70)$ & \\
\hline \multicolumn{4}{|l|}{ Contribution of the project to:* } \\
\hline Providing new knowledge about EBP in the ward & -- & $8.71(0.94)$ & \\
\hline Improved learning environment for students & -- & $8.73(0.84)$ & \\
\hline Improved learning environment for one self & -- & $8.76(0.75)$ & \\
\hline New routines in the daily work & -- & $9.00(1.62)$ & \\
\hline Improved quality of nursing care in the ward & -- & $8.92(0.72)$ & \\
\hline Improved own understanding about the importance of EBP & -- & $8.75(0.91)$ & \\
\hline Improved collaboration between academy and nurses in clinical area & -- & $8.90(0.85)$ & \\
\hline
\end{tabular}

Note. Mean values on a 10-point scale where $1=$ very low/very dissatisfied/very low importance and $10=$ very high/very satisfied/very high importance. Mann Whitney U test. *Measured at endpoint only.

It has long been a common understanding that nursing colleges and nursing administrators/leaders share responsibility in this matter. ${ }^{[35]}$ Nursing colleges are expected to educate both undergraduate and post graduate nurses about EBP and to collaborate with clinical practice in supporting nursing students and professionals in using EBP. ${ }^{[41,42]}$ Administrators and nursing leaders in different health care organisations have great responsibility for providing ongoing education, in-service training, and lifelong learning to nurses. ${ }^{[43,44]}$ Due to this assumption about shared responsibility, much research has highlighted the importance of partnership and collaboration between the academy and practice in achieving the goal of EBP. ${ }^{[45-47]}$ According to Harbman et al., ${ }^{[46]}$ collaboration and commitment from all partners can contribute to an evidence-based culture of inquiry, innovation, and system improvement. The fundamental idea of this study on the CMBP was to bring clinical practice and the academy together as equal partners in a joint effort to provide high quality care for patients and a good learning environment for both nursing students in their clinical placement and nurses in their daily work. The results indicate that these goals are attainable, which strengthens the usability of the model. Health care organisations are also responsible for providing the resources needed to implement EBP. ${ }^{[34]}$ The 
present study showed an expansion of available resources at the end of the project such as nurses' access to a research assistant and internet databases. We interpret this as an effect of the close collaboration between the nursing college and clinical practice during the project. The support of the project by head nurses and their superiors could also have affected the delivery of resources. However, the allocation of increased health care resources to supporting EBP will often be considered an extra cost, which could hinder its long-term implementation. According to Melnyk et al., ${ }^{[2]}$ among many others, this 'extra cost' should be considered temporary, as it reduces variations in practice and improves overall quality of care. An agreement between the academy and clinical practice about their shared responsibility and collaboration to achieve EBP has the potential to reduce costs. ${ }^{[48-50]}$

Finally, we argue that instead of continuing to measure nurses' attitudes to and knowledge of EBP, barriers, and promotors, per se, it is time for more studies into the systematic implementation, use, and evaluation of EBP. The present study used the CMBP collaborative model, but many other similar models may also be useful. What is crucial for their success is that EBP projects be long-lasting and adequately facilitated, since their implementation always involves a process of learning. ${ }^{[51]}$ If the focus of research into EBP does not shift to a more practical focus, suspicion could grow that measurements of EBP are proceeding for their own sake, instead of for the sake of improving the quality of nursing care.

\section{Methodological considerations}

This was a small-scale study involving a low number of participants from four wards in one hospital in India, which may limit its transferability. The high response rate (93/94\%) was satisfactory ${ }^{\left[{ }^{[52}\right]}$ however, as this was a unique project at the hospital, and data were gathered through self-reported scores on questionnaires, it is possible that the nurses on the wards felt singled out, which could have impacted positively on the results. Therefore, further similar studies would be valuable to improve the transferability of the results.

The main questionnaire used, the RUQ, has been validated in several other studies, and together with the additional study specific questions, it was pilot tested for the current study. There is now a considerable body of knowledge concerning

\section{REFERENCES}

[1] Kitson A. The State of the Art and Science of Evidence-Based Nursing in UK and Europe. Worldviews on Evidence-Based Nursing. 2004; 1(1): 6-8. PMid:17147753 https://doi.org/10.1111/j. $1741-6787.2004 .04010 . \mathrm{x}$

Published by Sciedu Press research utilisation, and individual factors associated with this are frequently described in the literature. Nevertheless, little is known about how robust these measures might be. ${ }^{[53]}$ The RUQ has been used in several studies and found to have good psychometric properties, but a Squires et al. ${ }^{[53]}$ showed in a review that its content validity and internal structure were poorly described in the 16 articles that reported its use. Squires et al. ${ }^{[53]}$ stressed that the RUQ does not measure research utilisation per se, but self-reported variables related to research utilisation, which is important to keep in mind when considering the results in this paper. Furthermore, the fact that the nurses scored high baseline values on the variables related to attitudes to research utilisation and EBP, knowledge of EBP, and use of EBP might be a sign of their overall positive attitude to the project itself when it was presented to them. If so, this may have had a false positive influence on the baseline results, but the fact that these values scored significantly higher in all items at the end of the project (20 months later) may strengthen the trustworthiness of the influence of the CMBP.

\section{Conclunsions}

The CMBP project was an attempt to improve the quality of care for patients and the learning environment for nurses and nursing students on the project wards, by means of collaboration between academy and clinical practice. The result showed that utilization of the model improved both the quality of care for patients, and the collaboration between academy and clinical practice. The CMBP also improved nurses' attitudes, knowledge and practices in regard to EBP, and the learning environment on the wards. Futhermore, the research resources available to the nurses, such as access to research assistants and internet databases increased, which was interpreted as an effect of the close academy - practice collaboration. These results indicated fulfilment of the goals of the project, which strengthens the usability of the model. Implementation of EBP is challenging and requires longlasting activities and comprehensive support from leaders and facilitators. More studies are needed in which EBP is systematically implemented, accomplished, evaluated, and reported.

\section{CONFlicts of InTERest Disclosure}

The authors declare that there is no conflict of interest.
[2] Melnyk B, Gallagher-Ford L, Long L, et al. The Establishment of Evidence-Based Practice Competencies for Practicing Registered Nurses and Advanced Practice Nurses in Real-World Clinical Settings: Proficiencies to Improve Healthcare Quality, Reliability, Patient Outcomes, and Costs. Worldviews on Evidence-Based Nursing. 
2014; 11(1): 5-15. PMid:24447399 https ://doi.org/10.1111/ wvn. 12021

[3] ICN. ICN Position Statement: Scope of nursing practice. 2013. International Council of Nursing.

[4] Royle J, Blythe J. Promoting research utilisation in nursing: the role of the individual, organisation, and environment. Evidence Based Nursing. 1998; 1(3): 71-72. https://doi .org/10.1136/ebn.1. 3.71

[5] Hudson K, Duke G, Haas B, et al. Navigating the evidence-based practice maze. Journal of Nursing Management. 2008; 16(4): 409416. PMid:18405257 https ://doi.org/10.1111/j.1365-283 4.2008.00860. $\mathrm{x}$

[6] Rycroft-Malone J. Evidence-informed practice: from individual to context. Journal of Nursing Management. 2008; 16(4): 404-408. PMid:18405256 https ://doi.org/10.1111/j.1365-2834.20 $08.00859 . \mathrm{x}$

[7] Dalheim A, Harthug S, Nilsen RM, et al. Factors influencing the development of evidence-based practice among nurses: a selfreport survey. BMC Health Services Research. 2012; 12(1): 367. PMid:23092366 https : //doi.org/10.1186/1472-6963-12-3 67

[8] Boström AM, Rudman A, Ehrenberg A, et al. Factors associated with evidence-based practice among registered nurses in Sweden: a national cross-sectional study. BMC Health Services Research. 2013; 13(1): 165. PMid:23642173 https://doi.org/10.1186/ 1472-6963-13-165

[9] Thompson DS, O'leary K, Jensen E, et al. The relationship between busyness and research utilization: it is about time. Journal of Clinical Nursing. 2008; 17(4): 539-548. PMid:18205684 https://doi.org/10.1111/j.1365-2702.2007.01981.x

[10] Solomons NM, Spross JA. Evidence-based practice barriers and facilitators from a continuous quality improvement perspective: an integrative review. Journal of Nursing Management. 2011; 19(1): 109 120. PMid:21223411 https://doi.org/10.1111/j.1365-283 4.2010.01144.x

[11] Thorsteinsson HS. Icelandic Nurses' Beliefs, Skills, and Resources Associated with Evidence-Based Practice and Related Factors: A National Survey. Worldviews on Evidence-Based Nursing. 2013; 10(2): 116-126. PMid:22765261 https://doi.org/10.1111/j. 1741-6787.2012.00260.x

[12] Stokke K, Olsen NR, Espehaug B, et al. Evidence based practice beliefs and implementation among nurses: a cross-sectional study. BMC Nursing. 2014; 13(1): 8. PMid:24661602 https: //doi.org/10.1186/1472-6955-13-8

[13] Barrett D. The clinical role of nurse lecturers: Past, present, and future. Nurse Education Today. 2007; 27(5): 367-374. PMid:16914233 https://doi.org/10.1016/j.nedt.2006.05.018

[14] Björkström ME, Johansson IS, Athlin EE. Is the humanistic view of the nurse role still alive - in spite of an academic education? Journal of Advanced Nursing. 2006; 54(4): 502-510. PMid:16671979 https://doi.org/10.1111/j.1365-2648.2006.03845.x

[15] Kitson A, Ahmed LB, Harvey G, et al. From research to practice: one organizational model for promoting research-based practice. Journal of Advanced Nursing. 1996; 23(3): 430-440. https : //doi.org/10.1111/j.1365-2648.1996.tb00003.x

[16] Mccormack B, Manley K, Kitson A, et al. Towards practice development - a vision in reality or a reality without vision? Journal of Nursing Management. 1999; 7(5): 255-264. https://doi.org/10 $.1046 / j .1365-2834.1999 .00133 . x$

[17] Rycroft-Malone J. The PARIHS Framework-A Framework for Guiding the Implementation of Evidence-based Practice. Journal of Nursing Care Quality. 2004; 19(4): 297-304. https ://doi.or g/10.1097/00001786-200410000-00002

[18] Rosswurm MA, Larrabee JH. A Model for Change to EvidenceBased Practice. Image: the Journal of Nursing Scholarship. 1999; 31(4): 317-322. PMid:10628096 https ://doi.org/10.1111/j . 1547-5069.1999.tb00510.x

[19] Morris J, Maynard V. The feasibility of introducing an evidence based practice cycle into a clinical area: An evaluation of process and outcome. Nurse Education in Practice. 2009; 9(3): 190-198. PMid:18707920 https ://doi.org/10.1016/j.nepr.2008.06 .002

[20] Foss JE, Kvigne K, Larsson BW, et al. A model (CMBP) for collaboration between university college and nursing practice to promote research utilization in students' clinical placements: A pilot study. Nurse Education in Practice. 2014; 14(4): 396-402. PMid:24398249 https://doi.org/10.1016/j.nepr.2013.11.008

[21] Bvumbwe T. Enhancing nursing education via academic-clinical partnership: An integrative review. International Journal of Nursing Sciences. 2016; 3(3): 314-322. https ://doi.org/10.1016/ j.ijnss.2016.07.002

[22] Bjuresäter K, Athlin E. Improvement of nursing care by means of the evidence based practice process: The facilitator role. Journal of Nursing Education and Practice. 2016; 6(11): 61-72. https : //doi.org/10.5430/jnep.v6n11p61

[23] Leach MJ. Evidence-based practice: A framework for clinical practice and research design. International Journal of Nursing Practice. 2006; 12: 248-251. PMid:16942511 https://doi.org/10.1111/ j.1440-172X. 2006.00587.x

[24] Champion VL, Leach A. Variables related to research utilization in nursing: an empirical investigation. Journal of Advanced Nursing. 1989; 14(9): 705-710. https://doi.org/10.1111/j.1365-264 8.1989.tb01634.x

[25] Pettengill MM, Gillies DA, Clark CC. Factors Encouraging and Discouraging the Use of Nursing Research Findings. Journal of Nursing Scholarship. 1994; 26(2): 143-148. https ://doi.org/10.1111/ j.1547-5069.1994.tb00934.x

[26] Humphris D, O'Halloran P, Littlejohns P, et al. Do diabetes nurse specialists utilise research evidence? Practical Diabetes International. 1999; 16(2): 47-50. https ://doi.org/10.1002/pdi.19601602 13

[27] Wallin L, Boström AM, Wikblad K, et al. Sustainability in changing clinical practice promotes evidence-based nursing care. Journal of Advanced Nursing. 2003; 41(5): 509-518. https ://doi.org/10 .1046/j.1365-2648.2003.02574.x

[28] McCloskey DJ. Nurses' perceptions of research utilization in a corporate health care system. J Nurs Scholarsh. 2008; 40(1): 39-45. PMid:18302590 https://doi.org/10.1111/j.1547-5069.20 $07.00204 . \mathrm{x}$

[29] Field A, Discovering statistics using IBM SPSS statistics. 4th ed. London: SAGE Publications. 2013.

[30] Karki S, Acharya R, Budhwani H, et al. Perceptions and Attitudes towards Evidence Based Practice among Nurses and Nursing Students in Nepal. Kathmandu University Medical Journal. 2017; 13(4): 308-315. https ://doi .org/10.3126/kumj .v13i4.16829

[31] Stavor DC, Zedreck-Gonzalez J, Hoffmann RL. Improving the Use of Evidence-Based Practice and Research Utilization Through the Identification of Barriers to Implementation in a Critical Access Hospital. Journal of Nursing Administration. 2017; 47(1): 56-61. PMid:27926624 https://doi.org/10.1097/NNA.0000000000 000437

[32] Adib-Hajbaghery M. Evidence-Based Practice: Iranian Nurses' Perceptions. Worldviews on Evidence-Based Nursing. 2009; 6(2): 93 
101. PMid:19413583 https://doi.org/10.1111/j.1741-678

$7.2009 .00149 . x$

[33] Gerrish K, Clayton J. Promoting evidence-based practice: an organizational approach. Journal of Nursing Management. 2004; 12(2): 114-123. https://doi.org/10.1111/j.1365-2834.2004.004 $54 . \mathrm{x}$

[34] Ubbink DT, Guyatt GH, Vermeulen H. Framework of policy recommendations for implementation of evidence-based practice: a systematic scoping review. BMJ Open. 2013; 3(1).

[35] Saunders H, Vehviläinen-Julkunen K. The state of readiness for evidence-based practice among nurses: An integrative review. International Journal of Nursing Studies. 2016; 56(Supplement C): 128140. PMid:26603729 https://doi.org/10.1016/j.ijnurstu .2015 .10 .018

[36] Ramos-Morcillo AJ, Fernández-Salazar S, Ruzafa-Martínez M, et al. Effectiveness of a Brief, Basic Evidence-Based Practice Course for Clinical Nurses. Worldviews on Evidence-Based Nursing. 2015; 12(4): 199-207. PMid:26220505 https ://doi .org/10.1111/wv n. 12103

[37] Reviriego E, Cidoncha MÁ, Asua J, et al. Online training course on critical appraisal for nurses: adaptation and assessment. BMC Medical Education. 2014; 14(1): 136. PMid:24996951 https: //doi.org/10.1186/1472-6920-14-136

[38] Kim SC, Brown CE, Ecoff L, et al. Regional Evidence-Based Practice Fellowship Program:Impact on Evidence-Based Practice Implementation and Barriers. Clinical Nursing Research. 2013; 22(1): 51-69. PMid:22645401 https://doi .org/10.1177/10547738124460 63

[39] Hines S, Kynoch K, Munday J, et al. Evidence-Based Practice Education for Better Knowledge, Attitudes, and Practices in Nurses and Midwives. The Journal of Continuing Education in Nursing. 2017; 48(6): 256-262. https://doi .org/10.3928/00220124-20170 517-05

[40] Underhill M, Roper K, Siefert ML, et al. Evidence-Based Practice Beliefs and Implementation Before and After an Initiative to Promote Evidence-Based Nursing in an Ambulatory Oncology Setting. Worldviews on Evidence-Based Nursing. 2015; 12(2): 70-78. PMid:25704058 https://doi .org/10.1111/wvn. 12080

[41] Brown CE, Wickline MA, Ecoff L, et al. Nursing practice, knowledge, attitudes and perceived barriers to evidence-based practice at an academic medical center. Journal of Advanced Nursing. 2009; 65(2): 371-381. PMid: 19040688

[42] Mehrdad N, Salsali M, Kazemnejad A. The spectrum of barriers to and facilitators of research utilization in Iranian nursing. Journal of Clinical Nursing. 2008; 17(16): 2194-2202. PMid:18710376 https://doi.org/10.1111/j.1365-2702.2007.02040.x
[43] Sandström B, Borglin G, Nilsson R, et al. Promoting the Implementation of Evidence-Based Practice: A Literature Review Focusing on the Role of Nursing Leadership. Worldviews on Evidence-Based Nursing. 2011; 8(4): 212-223. PMid:21401858 https ://doi .org/ $10.1111 / j .1741-6787.2011 .00216 . x$

[44] Wilkinson JE, Nutley SM, Davies HTO. An Exploration of the Roles of Nurse Managers in Evidence-Based Practice Implementation. Worldviews on Evidence-Based Nursing. 2011; 8(4): 236-246. PMid:21668735 https://doi.org/10.1111/j.1741-6787.20 $11.00225 . \mathrm{x}$

[45] Saunders H, Vehviläinen-Julkunen K. Nurses' Evidence-Based Practice Beliefs and the Role of Evidence-Based Practice Mentors at University Hospitals in Finland. Worldviews on Evidence-Based Nursing. 2017; 14(1): 35-45. PMid:28002654 https://doi.org/ 10.1111/wvn. 12189

[46] Harbman P, Bryant-Lukosius D, Martin-Misener R, et al. Partners in research: building academic-practice partnerships to educate and mentor advanced practice nurses. Journal of Evaluation in Clinical Practice. 2017; 23(2): 382-390. PMid:27804187 https://doi.org/10.1111/jep.12630

[47] Mccormack B. Engaged scholarship and research impact: integrating the doing and using of research in practice. Journal of Research in Nursing. 2011; 16(2): 111-127. https://doi.org/10.1177/17 44987110393419

[48] Milner F, Estabrooks C, Humphrey C. Clinical nurse educators as agents for change: increasing research utilization. International Journal of Nursing Studies. 2005; 42(8): 899-914. PMid:16210028 https://doi.org/10.1016/j.ijnurstu.2004.11.006

[49] Melnyk BM, Fineout-Overholt E, Gallagher-Ford L, et al. The State of Evidence-Based Practice in US Nurses: Critical Implications for Nurse Leaders and Educators. Journal of Nursing Administration. 2012; 42(9): 410-417. PMid:22922750 https://doi.org/10.1 097/NNA . Ob013e3182664e0a

[50] Travis L, Hart A, Hardin S, et al. Academic-service partnerships: Seven dimensions of successful collaboration. $\mathbf{J}$ of Nursing Education and Practice. 2013; 3(1): 1-12. https://doi.org/10.5430/ jnep.v3n1p1

[51] Nilsen P, Neher M, Ellström PE, et al. Implementation of EvidenceBased Practice From a Learning Perspective. Worldviews on Evidence-Based Nursing. 2017; 14(3): 192-199. PMid:28281328 https://doi.org/10.1111/wvn.12212

[52] Polit D, Beck C. Nursing research: generating and assessing evidence for nursing practice. 10th ed. Philadelphia: Lippincott Williams \& Wilkins. 2017.

[53] Squires JE, Estabrooks CA, O'rourke HM, et al. A systematic review of the psychometric properties of self-report research utilization measures used in healthcare. Implementation Science. 2011; 6(1): 83. PMid:21794144 https://doi.org/10.1186/1748-5908-6-83 